Original Research

\title{
Heterologous Oviductal Cells Binding Capacity of Cryopreserved Equine Ejaculated and Epididymal Spermatozoa
}

\author{
João Alexandre Matos Carneiro ${ }^{\mathrm{a}}$, Gabriel Augusto Monteiro ${ }^{\mathrm{b}}$, Ian Martin ${ }^{\mathrm{c}}$, \\ Roziaria Rosario Dias Maziero ${ }^{a}$, Yame Fabres Robaina Sancler-Silva ${ }^{a}$, \\ Camila de Paula Freitas-Dell'Aqua ${ }^{a}$, Priscilla Nascimento Guasti ${ }^{a}$, Rafael Bandeira ${ }^{a}$, \\ Felipe Pires Hartwig ${ }^{a}$, Fernanda Saules Ignácio ${ }^{\mathrm{d}}$, Fernanda da Cruz Landima ${ }^{\mathrm{a}}$, \\ Marco Antonio Alvarenga ${ }^{a}$, Frederico Ozanam Papa ${ }^{a}$, José Antonio Dell'Aqua Jr. ${ }^{a, *}$ \\ ${ }^{a}$ Faculdade de Medicina Veterinária e Zootecnia, UNESP, Univ Estadual Paulista, Botucatu, Brazil \\ ${ }^{\mathrm{b}}$ Escola de Veterinária, UFMG, Univ Federal de Minas Gerais, Belo Horizonte, Brazil \\ ${ }^{\mathrm{c}}$ Universidade de Uberaba, UNIUBE, Uberaba, Brazil \\ ${ }^{\mathrm{d}}$ Faculdade Integradas de Ourinhos, FIO, Ourinhos, Brazil
}

\section{A R T I C L E I N F O}

\section{Article history:}

Received 2 February 2017

Received in revised form 7 August 2017

Accepted 7 August 2017

Available online 19 August 2017

\section{Keywords:}

Stallion

Epididymis

Sperm reservoir

Oviductal cell culture

\begin{abstract}
A B S T R A C T
This study investigated the binding capacity of equine spermatozoa (both ejaculated and from different epididymal regions) to the oviductal epithelial cells (OECs) culture, before and after cryopreservation, using an oviduct explant assay. Ejaculated and epididymal sperm from caput, corpus, and cauda of 10 stallions were diluted and submitted to freezing process. Fresh and frozen-thawed sperm were evaluated for sperm kinematics, plasma membrane integrity (PMI) and incubated with oviduct explants. The cryopreservation process decreased significantly the sperm motility parameters of ejaculated sperm, and corpus and cauda epididymal sperm $(P<.05)$. The percentage of PMI was significant higher in fresh samples versus frozen-thawed samples, in all analyzed groups $(P<.05)$. Binding of ejaculated spermatozoa to oviduct epithelium was significantly higher than caput, corpus, or cauda epididymal sperm $(P<.05)$. The caput epididymal sperm showed no binding capacity to oviduct explants; thus, significantly more sperm recovered from the corpus and cauda epididymis were bound to OEC compared to caput epididymal sperm $(P<.05)$. No differences were observed in ejaculated and epididymal sperm before and after cryopreservation $(P>$ $.05)$. In conclusion, the ejaculated sperm has higher binding capacity than epididymal sperm, suggesting that the seminal plasma plays an important role in the establishment of the oviductal sperm reservoir. The cryopreservation process did not affect the binding capacity of ejaculated or epididymal spermatozoa to oviductal epithelium.
\end{abstract}

(ㄷ) 2017 Elsevier Inc. All rights reserved.

\footnotetext{
Animal welfare/ethical statement: Approved by the Ethics Committee on the use of animals (CEUA) of the College of Veterinary Medicine and Animal Science of Botucatu under protocol $n^{\circ}$. 89/2016. Ethical Aspects recommended by the Brazilian College of Animal Experimentation (COBEA).

Conflict of interests statement: The authors declare no conflict of interests.
}

* Corresponding author at: José Antonio Dell'Aqua Jr., Faculdade de Medicina Veterinária e Zootecnia, UNESP, Univ Estadual Paulista, Departamento de Reprodução Animal e Radiologia Veterinária, 18618-681, Botucatu, São Paulo, Brazil.

E-mail address: dellaquajunior@uol.com.br (J.A. Dell’Aqua). 


\section{Introduction}

The collection and cryopreservation of epididymal sperm plays an important role to preserve genetic information in cases of valuable deceased males, unexpected death, and catastrophic injury in which semen collection is not possible [1]. Relevant advances in stallion's epididymal sperm technology have been performed in the last years, resulting in a significant improvement of the viability and fertility of the recovered sperm cells [1-5]. Therefore, only cauda epididymal sperm is used in artificial insemination because the spermatozoa collected from the proximal segments are unable to fertilize an oocyte [6,7].

The cauda epididymal fluid provides an important environment for the sperm survival during storage maintaining the cells in a quiescent state, preserving the metabolism and fertilizing capacity $[8,9]$.

The unique composition of cauda fluid includes different secretory proteins either native or transported from proximal segments of the epididymis [10], specific enzymes [11], low concentration of luminal and intracellular calcium [12], sperm-proteases interaction (Rosettes) [13], acidic pH and low sodium, chloride, glutamate, and androgen concentrations [14]. However, it is well known that the ability of sperm to fertilize eggs is due to the modifications that occur in epididymal sperm from caput to caudal segments [15] and not to local factors.

Each anatomic region (caput, corpus, and cauda) of epididymis is characterized by its own secretory activity resulting in successive biochemical environments in which sequential interactions with the sperm membrane occur [16]. The differences of the microenvironment and sperm functionality along the epididymal transit may allow the development of sperm ability to bind to the oviductal epithelial cells (OECs) and consequently form the sperm reservoir.

Binding of epididymal bull sperm to epithelium occurs at a low level [17], but once they are coated with members of the bovine seminal plasma (BSP) proteins, their binding increases to the level of ejaculated sperm [18,19]. SP-1 and SP-2 are the most abundant proteins in equine seminal plasma [20], and they are the equine orthologs to the BSP, which have been shown to be involved in early fertilization steps [21].

Previous studies have shown a positive association between the in vitro capacity of sperm to bind to oviductal epithelium and fertility [22,23]. Furthermore, the sperm binding to oviductal epithelium has different functions, such as reducing the risk of polyspermy by releasing a gradual amount of sperm from the reservoir at the time of ovulation, preventing premature sperm capacitation [24] and maintaining sperm viability [25]. However, it is still largely unknown where and when spermatozoa develop this ability to bind to the oviductal epithelium and hence form the sperm reservoir. It is not clear whether this capacity begins to develop in the ejaculate or during sperm maturation in different regions of the epididymis. It is known that the maturation processes that occur to spermatozoa during their passage in the epididymal tract contribute to the biochemical changes to their plasma membrane [10], but the ability of the equine epididymal sperm to bind to OEC in vitro, especially among different regions of the epididymis, remains unknown.

The cryopreservation of spermatozoa recovered from epididymis allows the germplasm to be stored indefinitely in liquid nitrogen for future use, without a significant loss of fertility [3]. However, various sperm organelles are affected due to the detrimental effects of cryopreservation, such as induction of premature acrosomal reaction, altered mitochondrial function, cold shock, reduction of motility, and failure of chromatin decondensation, thereby affecting the viability and fertility of the cells [26-29]. In stallions, the cryopreservation of ejaculated sperm decreases the number of sperm binding to OEC and the length of time these sperm survive [30].

In order to investigate the binding potential of equine spermatozoa ejaculated and from different regions of the epididymis in the oviductal epithelium, before and after cryopreservation, a sperm binding study was performed using an oviduct explant assay.

\section{Materials and Methods}

All animal procedures were followed the guidelines for the ethical treatment and approved by the Institutional Animal Care and Use Committee of the School of Veterinary Medicine and Animal Science, São Paulo State University (UNESP), Botucatu, Brazil.

\subsection{Animals}

Ten stallions (six Andalusians and four Brazilian Sport Horse) aged between 34 and 38 months, clinically healthy were used. Prior to experiment, the animals were submitted to andrological examinations, and three ejaculates from each stallion were collected with an interval of 2 days.

\subsection{Sperm Collection}

\subsubsection{Ejaculated Sperm}

One ejaculate from each stallion was collected using an artificial vagina. After removal of the gel fraction, the semen was diluted in a skim milk-based extender (BotuSemen; Botupharma, Brazil) to a final concentration of $50 \times 10^{6}$ sperm/mL and transported at $15^{\circ} \mathrm{C}$ in a semen transport container (Botupharma) for approximately 60 minutes until arrival at the laboratory.

\subsubsection{Epididymal Sperm}

One week after semen collection, the stallions were submitted to bilateral orchiectomy. The surgical procedure was performed as described by Guasti et al [31], with modifications. The regional anesthesia was modified by applying $10 \mathrm{~mL}$ of $2 \%$ lidocaine (with epinephrine) under the scrotal skin along the incision line using a 21-gauge 1.25 -inch needle. After castration, the vas deferens was clamped; the testes were identified and placed in lactated Ringer's solution. Testes and epididymides were then transported at $15^{\circ} \mathrm{C}$ in a semen transport container (Botupharma) for approximately 60 minutes until arrival at the laboratory. 
The epididymis was isolated from the testis and divided into three regions (caput, corpus, and cauda) as described by Gatty et al [15]. Small segments ( $5 \mathrm{~mm}$ ) between each epididymal region were removed to avoid overlapping of different sperm population. The recovery of epididymal sperm was performed using the flotation technique described by Cary et al [32] with skim milk-based extender (BotuSemen; Botupharma). After recovery, the sperm concentration was set to $50 \times 10^{6} \mathrm{sperm} / \mathrm{mL}$.

\subsection{Cryopreservation of Ejaculated and Epididymal Sperm}

The cryopreservation process was performed according to the instructions supplied by the freezing extender manufacturer. The ejaculated and epididymal sperm were centrifuged at $600 \mathrm{~g}$ for 10 minutes. The supernatants were discarded, and sperm pellets were extended to a final concentration of $100 \times 10^{6} \mathrm{sperm} / \mathrm{mL}$ in an egg yolk-based freezing extender (BotuCrio, Botupharma) and packaged into $0.5-\mathrm{mL}$ straws. The sperm samples were transferred to a refrigerator (Minitub do Brasil, Brazil) and remained at a constant temperature of $5^{\circ} \mathrm{C}$ for 20 minutes. Subsequently, an isothermal box (Styrofoam box) of 42-L capacity was filled with a depth of 3.5-cm liquid nitrogen (N2). The straws were placed horizontally at $6 \mathrm{~cm}$ above the level of $\mathrm{N} 2$ for 20 minutes and then immersed into liquid nitrogen for storage [1].

\subsection{Sperm Evaluation}

The ejaculated sperm samples were evaluated after semen collection and after thawing, and the epididymal samples were evaluated after resuspension in the freezing extender and after thawing. The straws were thawed at $46^{\circ} \mathrm{C}$ for 20 seconds [33].

The motility parameters were evaluated by computerassisted sperm analysis (CASA; HTM IVOS 12) for total motility (TM, \%), progressive motility (PM, \%), and percentage of rapid sperm (RAP, \%). The CASA analysis setup was the same described by Guasti et al [30] (Table 1). Motility parameters were collected and recorded by the analysis of five random fields and at least 1,000 sperm cells.

The plasma membrane integrity (PMI) was evaluated at $\times 400$ magnification by epifluorescence microscopy (Leica Microsystems, DMLB, Wetzlar, Germany) using a 540- to 525-nm fluorescence excitation filter and a 605- to 655-nm fluorescence emission filter. The fluorescent probes carboxyfluorescein diacetate and propidium iodide were used to assess the PMI, as described by Harrison and Vickers [34]. Two hundred sperm cells were counted and evaluated per sample.

\subsection{Collection and Processing of Oviducts for Culture}

All chemicals and media were obtained from Life Technologies. For this study, bovine oviducts were chosen due to the proximity of the slaughterhouse and easy accessibility. Furthermore, previous studies demonstrated that it is possible to perform sperm binding tests in coculture with OECs from different species [30,35].
Table 1

Setup parameters from Center of Study in Animal Reproduction (CERAN, FMVZ, UNESP, Botucatu, Brazil) used in CASA system analysis in stallions.

\begin{tabular}{ll}
\hline Characteristic & Setup \\
\hline Image capture (frames per second) & $60 \mathrm{~Hz}$ \\
Image capture (No. of frames) & 30 \\
Cell detection (min contrast) & 30 \\
Cell detection (min cell size) & 30 pixels \\
Defaults (cell size) & 5 pixels \\
Defaults (cell intensity) & 40 \\
Progressive cells (VAP) & $70.0 \mu / \mathrm{s}$ \\
Progressive cells (STR) & $80.0 \%$ \\
Slow cells (static: VAP cutoff) & $30 \mu / \mathrm{s}$ \\
Slow cells (static: VSL cutoff) & $20 \mu / \mathrm{s}$ \\
Illumination: intensity & 3,600 \\
Illumination: photometer & 125 \\
Video source (dark field) & $60 \mathrm{~Hz}$ \\
Static intensity gates (min and max) & 0.48 and 1.45 \\
Static elongation gates (min and max) & 0 and 97 \\
Chamber type & Makler \\
Temperature & $38^{\circ} \mathrm{C}$ \\
Field selection & Automatic \\
\hline
\end{tabular}

Abbreviations: CASA, computer-assisted sperm analysis; VAP, average path velocity; STR, straightness.

a Hamilton Thorne Research, Beverly, MA, USA (chamber depth $10.0 \mu \mathrm{m}$, stage position $14.3 \mathrm{~mm}$ ).

Oviducts were obtained at a slaughterhouse from pubertal Nelore heifers aged 13-15 months and transported to the laboratory in a prewarmed $\left(38.5^{\circ} \mathrm{C}\right) 0.9 \%$ sodium chloride solution for approximately 40 minutes. Upon arrival, the oviducts were cleaned and washed using prewarmed $\left(37^{\circ} \mathrm{C}\right)$ lactated Ringer's solution and separated from ligaments and blood vessels. Only oviducts which ovaries did not show any signs of cyclicity such as follicular growth, ovulation, or the presence of corpus luteum were selected. A "pool" of oviducts was performed in order to eliminate the individual effect of the female. The collection of oviductal epithelium and cell culture was performed as described by Petrunkina et al [36] and Wagner et al [37] with modifications. A section after uterotubal junction, approximately $4 \mathrm{~cm}$ long, was cut and used to obtain OECs. The segments were placed in a $60 \times 16 \mathrm{~mm}$ Petri dish (TPP, Switzerland) containing tissue culture medium (TCM 199) supplemented with $10 \%$ fetal bovine serum (FBS), $5 \mu \mathrm{g} / \mathrm{mL}$ insulin, $5 \mu \mathrm{g} / \mathrm{mL}$ transferrin, $5 \mathrm{ng} / \mathrm{mL}$ selenium, and $25 \mu \mathrm{g} /$ $\mathrm{mL}$ gentamicin sulfate. Each oviduct segment was clamped in the isthmus using a sterile hemostat and squeezed by pressure with a glass slide to recover the OECs.

The OEC suspension was aspirated using a 1-mL micropipette and transferred to Petri dishes $(60 \times$ $16 \mathrm{~mm}$ ) containing $20 \mathrm{~mL}$ prewarmed $\left(38.5^{\circ} \mathrm{C}\right)$ supplemented TCM 199. The cells were gently mixed and disaggregated by being passed once through a 25-gauge needle. The suspensions were washed twice at $200 \mathrm{~g}$ for 10 minutes at room temperature, OEC were extended in $10 \mathrm{~mL}$ supplemented TCM 199, and then transferred into 6-cm Petri dishes.

The $\mathrm{OEC}$ were incubated at $38.5^{\circ} \mathrm{C}$ under an atmosphere of $5 \% \mathrm{CO}_{2}$ and $100 \%$ humidity for 24 hours. After this period, the OEC organized in aggregates (explants) exhibiting vigorous ciliary activity was selected, and OEC with poor ciliary activity was discarded. 


\subsection{Sperm Preparation}

Epididymal and ejaculated sperm samples (fresh and frozen thawed) were washed by a density gradient (EquiPure, Nidacon, Sweden) at $900 \mathrm{~g}$ for 5 minutes to remove the semen extender. The supernatant was discarded, and the sperm pellet was extended to a final concentration of $0.5 \times 10^{6} \mathrm{sperm} / \mathrm{mL}$ per drop in $50-\mu \mathrm{L}$ human tubal fluid (HTF, Irvine Scientific) containing $5 \mathrm{mg} / \mathrm{mL}$ bovine serum albumin, $11 \mathrm{mg} / \mathrm{mL}$ sodium pyruvate, $0.5 \mathrm{mg} / \mathrm{mL}$ caffeine, $3 \mathrm{mg} / \mathrm{mL}$ heparin, $0.3 \mathrm{mg} / \mathrm{mL}$ penicillin-amine, $0.11 \mathrm{mg} / \mathrm{mL}$ hypotaurine, $0.18 \mathrm{mg} / \mathrm{mL}$ epinephrine, and $16.67 \mu \mathrm{g} / \mu \mathrm{L}$ amikacin sulfate.

\subsection{Sperm-Oviduct Binding}

The experimental trials were established by adding different sperm suspensions to the oviduct explants, which were: (1) fresh ejaculated sperm; (2) fresh caput epididymal sperm; (3) fresh corpus epididymal sperm; (4) fresh cauda epididymal sperm; (5) frozen-thawed ejaculated sperm; (6) frozen-thawed caput epididymal sperm; (7) frozen-thawed corpus epididymal sperm; and (8) frozenthawed cauda epididymal sperm. A final concentration of $0.5 \times 10^{6} \mathrm{sperm} / \mathrm{mL}$ was added to the oviduct explantcontaining droplet for each group. The droplets were incubated at $38.5^{\circ} \mathrm{C}$ in a humidified atmosphere of $5 \% \mathrm{CO}_{2}$ in air for 30 minutes and cultured under mineral oil to prevent evaporation.

\subsection{Quantification of Sperm Binding to Oviductal Epithelium}

After coincubation, the sperm-oviduct explants were washed in drops of HTF for removal of unbound spermatozoa and transferred to a warm glass slide and examined using a differential interference contrast microscope (Leica DM 2500, Leica Microsystems GmbH, Germany) coupled to a digital camera (Leica DFC295, Leica Microsystems), at a magnification of $\times 40$. Two images were captured per sperm-oviduct explant. The number of bound spermatozoa was counted at the edges and explant surface. The surface area was included in the quantification of binding due to surface variation and heterogeneity of sperm binding. The surface area of the oviduct explant was measured with ImageJ software (National Institutes of Health) to calculate the number of spermatozoa bound to the oviductal explant per $\mathrm{mm}^{2}$, dividing the number of sperm bounded by the surface explant area.

\subsection{Scanning Electron Microscopy}

The preparation for scanning electron microscopy was the same described by Martins et al [38]. Sperm-oviductal explants cultures were fixed in $2.5 \%$ glutaraldehyde for 48 hours and then washed in phosphate buffer, $0.1 \mathrm{M}, \mathrm{pH}$ 7.3. Samples were postfixed in $1 \%$ osmium tetroxide solution, washed in phosphate buffer, dehydrated in alcohol solutions at increasing concentrations, $75 \%-100 \%$, and dried in a critical point device (Balzers CPD-020, Liechtenstein) using liquid carbon dioxide. The specimens were mounted on a metal base using silver glue and covered with gold in a device (Balzers MED-01, Liechtenstein) before being observed with an scanning electron microscope at increasing magnifications (model Quanta 200 FEG; FEI Company, EUA), under 15 KV tension.

\subsection{Statistical Analyses}

Data were checked for normality by KolmogorovSmirnov test. The comparison of sperm parameters and sperm binding index to OECs between the groups was analyzed by analysis of variance followed by Tukey's test. The effect of cryopreservation was analyzed by Student's $t$ test. Statistical analyses were performed using InStat 5.0 computational program (GraphPad Software Inc). Treatments were considered different if $P \leq .05$.

\section{Results}

\subsection{Comparison Between Ejaculated and Epididymal Spermatozoa}

No differences were observed in fresh ejaculated or cauda epididymal sperm for TM and RAP $(P>.05$; Fig. 1). However, PM was higher in ejaculated sperm versus epididymal sperm recovered from caput, corpus, and cauda $(P<.05$; Fig. 1). Plasma membrane integrity was lower in fresh caput epididymal sperm versus ejaculated sperm, and corpus and cauda epididymal sperm $(P<.05$; Fig. 1$)$.

After thawing, the total and PM and \%RAP were significantly higher in ejaculated spermatozoa compared to epididymal spermatozoa $(P<.05 ;$ Fig. 2$)$. As observed in fresh samples, the post-thaw PMI of frozen-thawed caput epididymal sperm was decreased in relation to ejaculated sperm, and corpus and cauda epididymal sperm $(P<.05 ;$ Fig. 2$)$.

The cryopreservation process decreased significantly the sperm motility parameters of ejaculated sperm, and corpus and cauda epididymal sperm $(P<.05$; Table 2$)$. Despite the fact that the fresh and frozen-thawed caput epididymal sperm had reduced values in sperm kinematics, it was not affected by the cryopreservation $(P>.05$; Table 2). Also, the percentage of PMI was significant higher in fresh samples versus frozen-thawed samples, in all analyzed groups $(P<.05$; Table 2$)$.

\subsection{Sperm-Oviduct Binding Assay}

The use of a bovine oviduct explant model (Fig. 3A) to coincubate equine sperm cells was efficient, by spermatozoa were observed interacting with oviductal cells, after culture (Fig. 3B; Fig. 4).

After 30 minutes of coincubation, significantly more ejaculated spermatozoa were bound per $\mathrm{mm}^{2}$ of oviduct epithelium compared to spermatozoa recovered from caput, corpus, or cauda epididymis $(P<.05$; Table 3$)$. The caput epididymal sperm showed no binding capacity to oviduct explants (Table 3 ); thus, significantly more sperm recovered from the corpus and cauda epididymis were bound to OEC compared to caput epididymal sperm $(P<$ .05; Table 3). The cryopreservation process did not affect the binding capacity of ejaculated or epididymal spermatozoa $(P>.05$; Table 3$)$. 


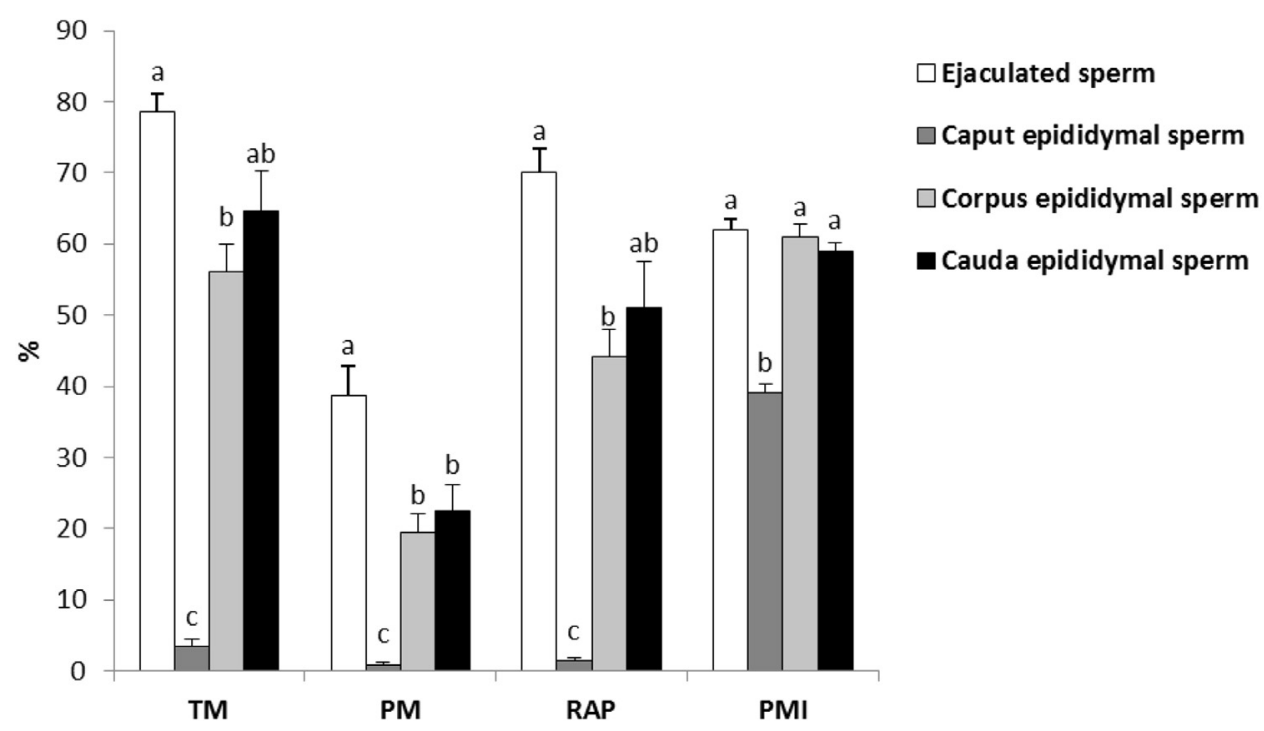

Fig. 1. Sperm kinetics parameters and plasma membrane integrity of fresh ejaculated sperm; and caput, corpus, and cauda epididymal sperm (means \pm SEM; $n=$ 10). ${ }^{\mathrm{a}-\mathrm{b}-\mathrm{c} P}<.05$. PM, progressive motility; PMI, plasma membrane integrity; RAP, rapid cells; SEM, standard error of the mean; TM, total motility.

\section{Discussion}

In the present study, we investigated the binding capacity of ejaculated and epididymal spermatozoa to OECs, before and after the cryopreservation process. Initially, the sperm kinematics and viability from the different groups were studied.

The acquisition of sperm motility during the posttesticular maturation in the epididymis is well established [15]. The present study demonstrated an increased number of motile cells in corpus and cauda epididymis compared to caput epididymis, suggesting that the equine sperm motility develops mainly from the corpus epididymis. Furthermore, this hypothesis is supported by several changes in the maturation accomplished during epididymal transit that facilitates sperm motility [39]. These modifications include changes in cAMP concentrations between epididymal regions [40], decrease in intracellular
$\mathrm{pH}$ [15], decrease in free calcium ion concentration and glucose transport in sperm [41], and decrease in mitochondrial calcium ion exchange [42].

The spermatozoa from the caput epididymis exhibited a failed capacity of movement at this initial stage of maturation, even after dilution in the freezing extender, according to our results. The intraluminal $\mathrm{pH}$ and bicarbonate concentration are known to mediate the sperm motility in epididymis [43]. In bulls, the $\mathrm{pH}$ of the epididymal cauda fluid ( $\mathrm{pH}$ 6.5) is lower than in initial segments ( $\mathrm{pH} 7.2$ ), and the bicarbonate concentration decreases from the rete testis fluid (30 mM) to cauda epididymitis (3-4 mM) [43], which might be related to the quiescence of the spermatozoa observed in caput epididymis. Interestingly, the PMI was lower in caput epididymal sperm than corpus and cauda epididymal sperm. These results are reinforced by others studies which reported that the progressive movement ability and the modifications on sperm lipid

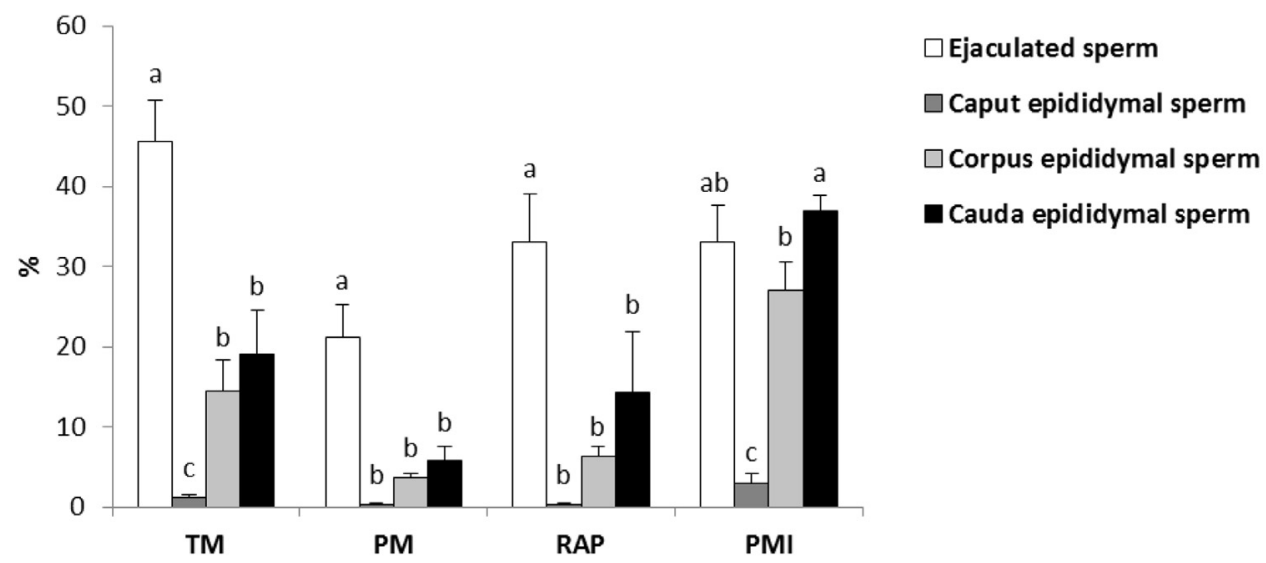

Fig. 2. Sperm kinetics parameters and plasma membrane integrity of frozen-thawed ejaculated sperm; and caput, corpus, and cauda epididymal sperm (means \pm SEM; $\mathrm{n}=10$ ). ${ }^{\mathrm{a}-\mathrm{b}-\mathrm{c} P}<.05$. PM, progressive motility; PMI, plasma membrane integrity; RAP, rapid cells; SEM, standard error of the mean; TM, total motility. 
Table 2

Sperm kinematics and plasma membrane integrity of ejaculated sperm; and caput, corpus, and cauda epididymal sperm before and after cryopreservation (means $\pm \mathrm{SEM} ; \mathrm{n}=10$ ).

\begin{tabular}{|c|c|c|c|c|}
\hline \multirow[t]{2}{*}{ Origin } & \multicolumn{4}{|l|}{ Variables } \\
\hline & TM (\%) & PM (\%) & RAP (\%) & PMI (\%) \\
\hline \multicolumn{5}{|l|}{ Fresh sperm } \\
\hline Ejaculated & $78.6 \pm 2.6^{\mathrm{Aa}}$ & $38.7 \pm 4.1^{\mathrm{Aa}}$ & $70.1 \pm 3.4^{\mathrm{Aa}}$ & $62 \pm 1.4^{\mathrm{Aa}}$ \\
\hline Caput & $3.4 \pm 1.0^{\mathrm{Ca}}$ & $0.9 \pm 0.3^{\mathrm{Ca}}$ & $1.4 \pm 0.5^{\mathrm{Ca}}$ & $39 \pm 1.4^{\mathrm{Ba}}$ \\
\hline Corpus & $56.2 \pm 3.8^{\mathrm{Ba}}$ & $19.5 \pm 2.5^{\mathrm{Ba}}$ & $44.1 \pm 3.9^{\mathrm{Ba}}$ & $61 \pm 1.7^{\mathrm{Aa}}$ \\
\hline Cauda & $64.7 \pm 5.5^{\mathrm{ABa}}$ & $22.4 \pm 3.8^{\mathrm{Ba}}$ & $51.0 \pm 6.5^{\mathrm{ABa}}$ & $59 \pm 1.2^{\mathrm{Aa}}$ \\
\hline \multicolumn{5}{|c|}{ Frozen-thawed sperm } \\
\hline Ejaculated & $45.6 \pm 5.1^{\mathrm{Ab}}$ & $21.1 \pm 4.1^{\mathrm{Ab}}$ & $33.0 \pm 6.0^{\mathrm{Ab}}$ & $33 \pm 4.6^{\mathrm{ABb}}$ \\
\hline Caput & $1.1 \pm 0.5^{\mathrm{Ca}}$ & $0.3 \pm 0.1^{\mathrm{Ba}}$ & $0.3 \pm 0.1^{\mathrm{Ba}}$ & $3 \pm 1.1^{\mathrm{Cb}}$ \\
\hline Corpus & $14.4 \pm 3.9^{\mathrm{Bb}}$ & $3.6 \pm 0.6^{\mathrm{Bb}}$ & $6.3 \pm 1.2^{\mathrm{Bb}}$ & $27 \pm 3.6^{\mathrm{Bb}}$ \\
\hline Cauda & $19.1 \pm 5.4^{\mathrm{Bb}}$ & $5.8 \pm 1.7^{\mathrm{Bb}}$ & $14.3 \pm 7.5^{\mathrm{Bb}}$ & $37 \pm 1.9^{\mathrm{Ab}}$ \\
\hline
\end{tabular}

Abbreviations: PM, progressive motility; PMI, plasma membrane integrity; RAP, rapid cells; SEM, standard error of the mean; TM, total motility. Superscript with different letters $(\mathrm{a} / \mathrm{b})$ between treatments differ significantly $(P<.05)$.

Superscript with different letters $(A / B / C)$ within treatments differ significantly $(P<.05)$

composition appear specifically in the corpus region due to its biochemical environment $[12,44]$.

The sperm cryopreservation is an essential procedure to preserve sperm cells and can be applied for epididymal sperm to ensure the preservation of the genetic material from endangered species or sudden death [1]. The frozen epididymal sperm can be stored for a long period of time [3]; however, our results demonstrated that the freezethawing process causes reduction of sperm motility and viability in ejaculated and epididymal sperm.

The sperm kinematics of frozen-thawed ejaculated sperm were higher than corpus and cauda epididymal sperm, contrary to previous reports in horses $[2,3,45,46]$, pigs [47], and goats [48], which observed that the motility parameters and PMI after thawing were similar in ejaculated and epididymal sperm [3]. Moreover, the TM and PM of cauda epididymal sperm were lower than that described by Papa et al [1] and Monteiro et al [3]; probably, the age factor may have influenced the results as stallions aged between 34 and 38 months were used.
In the current study, an ex vivo equine sperm-oviduct binding assay was used to mimic the events that take place in the oviduct before fertilization. The use of a heterologous system for studying sperm binding to the oviductal epithelium has been examined in several species including the binding of human spermatozoa to the oviducts of cows and macaques [35], canine sperm to porcine oviducts [49], and stallion sperm to bovine oviductal cells $[21,30]$.

With regard to the quantification of sperm-oviduct binding, the cauda epididymal sperm exhibited a higher binding capacity, followed by epididymal corpus and caput. These results imply that sperm undergo developmental changes as they pass through the epididymis which appears to increase their capacity to bind to the oviductal epithelium.

The binding capacity of the ejaculated sperm to oviduct explants was higher than the epididymal sperm; this finding was similar to other study in pigs [36]. The interaction of ejaculated sperm with the secretions of the accessory glands, which are responsible for secreting large quantities of phospholipids, especially lecithins, play a role in sperm binding to OECs [24,50,51] and may have influenced the binding ability of ejaculated sperm in this study.

Furthermore, the seminal plasma proteins are involved in the establishment of the oviductal sperm reservoir $[18,52]$. The sperm binding to oviductal epithelium has been shown to involve carbohydrate-protein interactions [53]. The porcine spermadhesins, AQN-type proteins, are associated with the sperm surface at ejaculation and contribute to the formation of the oviductal sperm reservoir through interaction with the glycoconjugates of the oviductal epithelium [37,47]. The PDC-19 proteins are secreted by the seminal vesicles of the bull, and these proteins are attached to the sperm membrane during ejaculation and bind to fucosylated molecules in the oviductal epithelium [20]. Also, in the domestic cat, the seminal fluid promotes in vitro sperm-oviduct binding [54]. The formation of oviductal sperm reservoir in the mare is poorly understood. Our results suggest that the seminal plasma plays an important role in sperm binding to OECs
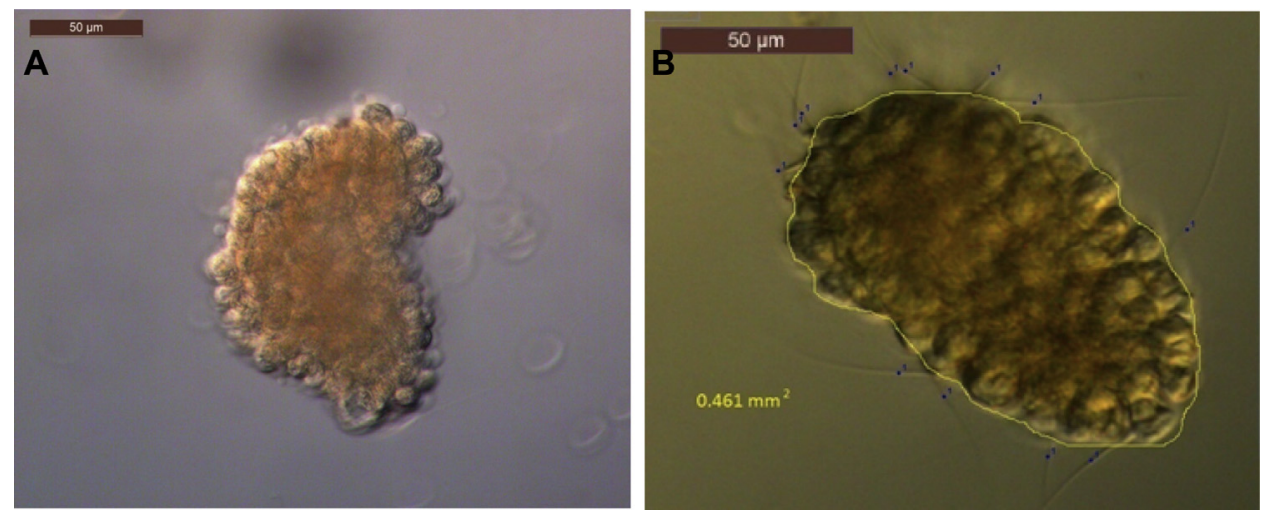

Fig. 3. Differential interference contrast light photomicrograph of (A) bovine oviductal epithelial cells organized in a suspended aggregate after 24-hour cell culture and (B) sperm-oviduct explant after 30-minute coincubation. Bound spermatozoa (B; blue dots) and explant perimeter (yellow line) were calculated to evaluate the number of spermatozoa bound to the oviductal explant per $\mathrm{mm}^{2}$. Magnification $\times 40 ; \mathrm{bar}=50 \mu \mathrm{m}$. 

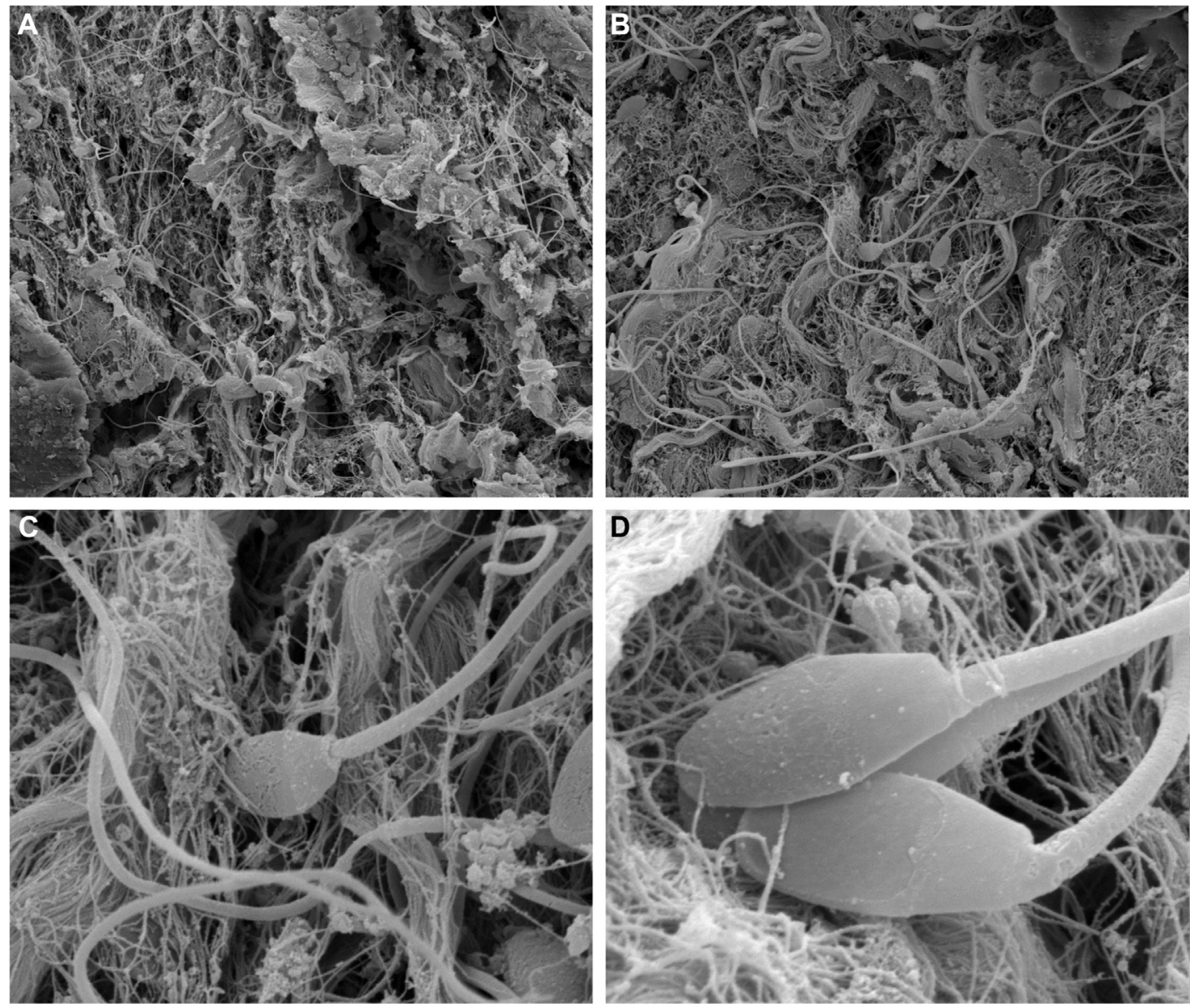

Fig. 4. Scanning electron micrographs of bovine oviductal cells taken 30 minutes after the addition of equine spermatozoa. (A) A view of the sperm-oviductal explant culture $(\times 1,613)$. (B) A higher magnification of the same culture $(\times 3,180)$. (C and D) Spermatozoa can be seen in contact with epithelial cell (C; $\times 1,400)(D ; \times 25,536)$. Note how the cilia surround the sperm cell.

and consequently the establishment of the oviductal sperm reservoir, as more ejaculated spermatozoa were bound to oviduct explant compared to epididymal sperm.

The sperm cryopreservation causes damage to plasma membrane [55], leading to a reduced number of sperm with the ability to bind to oviductal cells [36]. However, in this study, the cryopreservation process did not affect the binding capacity of ejaculated or epididymal spermatozoa, unlike other studies that observed a decrease in binding capacity of frozen-thawed sperm to OECs $[47,51,56]$. Factors such as the freezing extender and/or freezing protocol used in this study may have provided greater protection to sperm during the cryopreservation process, preserving the binding capacity of ejaculated and epididymal sperm cells.

\section{Conclusion}

The sperm kinematics and oviduct binding assay revealed a progressive development on motility, viability, and binding capacity of epididymal sperm, according to epididymis region and maturation stage of spermatozoa. The higher binding capacity of ejaculated sperm to oviduct explants suggests that the seminal plasma plays an important role in the establishment of the oviductal sperm

Table 3

Binding capacity of ejaculated and epididymal spermatozoa, before and after cryopreservation, to oviduct epithelium after 30 minutes of culture (means \pm SEM).

\begin{tabular}{lllll}
\hline Treatment & Ejaculated $\left(\mathrm{sptz} / \mathrm{mm}^{2}\right)$ & Caput $\left(\mathrm{sptz} / \mathrm{mm}^{2}\right)$ & Corpus $\left(\mathrm{sptz} / \mathrm{mm}^{2}\right)$ & Cauda $\left(\mathrm{sptz} / \mathrm{mm}^{2}\right)$ \\
\hline Fresh sperm & $88.2 \pm 13.5^{\mathrm{Aa}}$ & $0 \pm 0^{\mathrm{Ac}}$ & $6.7 \pm 1.9^{\mathrm{Ab}}$ & $17.8 \pm 9.4^{\mathrm{Ab}}$ \\
Frozen-thawed sperm & $72.8 \pm 6.8^{\mathrm{Aa}}$ & $0 \pm 0^{\mathrm{Ac}}$ & $9.8 \pm 1.2^{\mathrm{Ab}}$ & $17.7 \pm 2.3^{\mathrm{Ab}}$ \\
\hline
\end{tabular}

Abbreviations: SEM, standard error of the mean; Sptz, spermatozoa.

Superscript with different letters $(\mathrm{a} / \mathrm{b} / \mathrm{c})$ in the same row differ significantly $(P<.05)$.

Superscript with different letters $(\mathrm{A} / \mathrm{B})$ in the same column differ significantly $(P<.05)$. 
reservoir. Also, the cryopreservation process did not affect the binding capacity of ejaculated or epididymal spermatozoa to oviductal epithelium.

\section{Acknowledgments}

This work was supported by grant nos. 2012/12526-4 and 2012/17320-5 from the São Paulo Research Foundation (FAPESP).

\section{References}

[1] Papa FO, Melo CM, Fioratti EG, Dell'Aqua Jr JA, Zahn FS, Alvarenga MA. Freezing of stallion epididymal sperm. Anim Reprod Sci 2008;107:293-301.

[2] Morris L, Tiplady C, Allen WR. The in vivo fertility of cauda epididymal spermatozoa in the horse. Theriogenology 2002;58:643-6.

[3] Monteiro GA, Papa FO, Zahn FS, Dell'Aqua Jr JA, Melo CM, Mazieiro RRD, Avanzi BR, Alvarenga MA, Guasti PN. Cryopreservation and fertility of ejaculated and epididymal stallion sperm. Anim Reprod Sci 2011;127:197-201.

[4] Olaciregui M, Gil L, Montón A, Luño V, Jerez RA, Martí JI. Cryopreservation of epididymal stallion sperm. Cryobiology 2013;68(1): 91-5.

[5] Stawicki RJ, McDonnell SM, Giguère S, Turner RM. Pregnancy outcomes using stallion epididymal sperm stored at $5^{\circ} \mathrm{C}$ for 24 or 48 hours before harvest. Theriogenology 2016;85:698-702.

[6] Monteiro GA, Sancler-Silva YFR, Ramires-Neto C, FreitasDell'Aqua CP, Hartwig FP, Martin I, Crespilho AM, Alvarenga MA, Papa FO. Comparison of sperm parameters and fertility between sperm cryopreserved from ejaculated semen and from the epididymis of subfertile stallions. J Equine Vet Sci 2014;34:71.

[7] El-Badry DA, Scholkamy TH, Anwer Abeer M, Mahmoud Karima GhM. Assessment of Freezability and functional integrity of Dromedary Camel spermatozoa Harvested from caput, corpus and cauda epididymides. Alexandria J Vet Sci 2015;44: $147-58$.

[8] Nonakaa MI, Zsigmondb E, Kudoc A, Kawakami H, Yoshida K, Yoshida M, Kawanof N, Miyadof K, Nonakaa M, Wetsel RA. Epididymal C4b-binding protein is processed and degraded during transit through the duct and is not essential for fertility. Immunobiology 2015;220:467-75.

[9] Dacheux JL, Dacheux F, Druart X. Epididymal protein markers and fertility. Anim Reprod Sci 2016;169:76-87.

[10] Dacheux JL, Castella S, Gatti JL, Dacheux F. Epididymal cell secretory activities and the role of proteins in boar sperm maturation. Theriogenology 2005;63:319-41.

[11] Phopin K, Nimlamool W, Bartlett MJ, Bean BS. Distribution, crypticity, stability, and localization of a-L-fucosidase of mouse cauda epididymal sperm. Mol Reprod Development 2012;79:208-17.

[12] Dacheux JL, Dacheux F. New insights into epididymal function in relation to sperm maturation. Reproduction 2014;147:27-42.

[13] Monclus MA, Andreina C, Cabrillana ME, Saez Lancellotti TE, Rensetti DE, Clementi MA, et al. Protein fraction isolated from epididymal fluid re-associates sperm in vitro: possible role of serpins in rat rosettes assembly. Mol Reprod Dev 2010;77:410-9.

[14] Turner TT. Necessity's portion: inorganic ions and small organic molecules in the epididymal lumen. In: Robaire B, Hinton BT, editors. The epididymis: from molecules to clinical Practice. A Comprehensive Survey of the Efferent Ducts, the epididymis, and the vas deferens. New York: Kluwer Academic/Plenum Publishers; 2002. p. 146

[15] Gatti JL, Castella S, Dacheux F, Ecroyd H, Metayer S, Thimon V, et al Post-testicular sperm environment and fertility. Anim Reprod Sci 2004;82-83:321-39.

[16] Fouchécourt S, Métayer S, Locatelli A, Dacheux F, Dacheux JL. Stallion epididymal fluid Proteome: Qualitative and Quantitative characterization; secretion and Dynamic changes of Major proteins. Biol Reprod 2000;62:1790-803.

[17] Suarez SS. Regulation of sperm storage and movement in the mammalian oviduct. Int J Dev Biol 2008;52:455-62.

[18] Gwathmey TM, Ignotz GG, Suarez SS. PDC-109 (BSP-A1/A2) promotes bull sperm binding to oviductal epithelium in vitro and may be involved in forming the oviductal sperm reservoir. Biol Reprod 2003;69:809-15.
[19] Gwathmey TM, Ignotz GG, Mueller JL, Manjunath P, Suarez SS. Bovine seminal plasma proteins PDC-109, BSP-A3, and BSP-30- kDa share functional roles in storing sperm in the oviduct. Biol Reprod 2006:75:501-7.

[20] Ekhlasi-Hundrieser M, Gohr K, Wagner A, Tsolova M, Petrunkina A, Töpfer-Petersen E. Spermadhesin AQN1 is a candidate receptor molecule involved in the formation of the oviductal sperm reservoir in the pig. Biol Reprod 2005;73:536-45.

[21] Töpfer-Petersen E, Ekhlasi-Hundrieser M, Kirchhoff C, Leeb T, Sieme $\mathrm{H}$. The role of stallion seminal plasma proteins in fertilisation. Anim Reprod Sci 2005;89:159-70.

[22] De Pauw IMC, Van Soom A, Laevens H, Verberckmoes S, De Kruif A. Sperm binding to epithelial explants in bulls with different non-return rates investigated with a new in vitro model. Biol Reprod 2002;67:1073-9.

[23] Waberski D, Magnus F, Mendonca Ferreira F, Petrunkina AM, Weitze KF, Töpfer-Petersen E. Importance of sperm-binding assays for fertility prognosis of porcine spermatozoa. Theriogenology 2005;63:470-84.

[24] Töpfer-Petersen E, Wagner A, Friedrich J, Petrunkina A, EkhlasiHundriesen M, Waberski D, et al. Function of the mammalian oviductal sperm reservoir. J Exp Zool 2002;292:210-5.

[25] Newcombe JR, Cuervo-Arango J. The effect of time of Breeding relative to ovulation on Pregnancy rate when using cooled transported semen or Natural mating in the mare. J Equine Vet Sci 2015; 35:956-9.

[26] Morris GJ, Faszer K, Green JE, Draper D, Grout BWW, Fonseca F. Rapidly cooled horse spermatozoa: loss of viability is due to osmotic imbalance during thawing, not intracellular ice formation. Theriogenology 2007;68:804-12.

[27] Klewitz J, Hagen C, Behrendt D, Martinsson G, Sieme H. Effect of multiple freezing of stallion semen on sperm quality and fertility. Anim Reprod Sci 2008;107:327-8.

[28] Burnaugh L, Ball BA, Sabeur K, Thomas AD, Meyers AS. Osmotic stress stimulates generation of superoxide anion by spermatozoa in horses. Anim Reprod Sci 2010;117:249-60.

[29] Castro LS, Hamilton TRS, Mendes CM, Nichi M, Barnabe VH, Visintin JA, Assumpção MEOA. Sperm cyodamage occurs after rapid freezing phase: flow cytometry approach and antioxidant enzymes activity at different stages of cryopreservation. J Anim Sci Biotechnol 2016;7:17.

[30] Samper J, Ellington J, Burnett K, Jones A, Wright R. Use of sperm and oviduct cell co-culture as a test for stallion field fertility. Am Assoc Equine Pract 1995;41:3-5.

[31] Guasti PN, Monteiro GA, Maziero RR, Martin I, Avanzi BR, Dell'Aqua Jr JA, Papa FO. Effects of pentoxifylline on equine epididymal sperm. J Equine Vet Sci 2013;33:1153-6.

[32] Cary JA, Madill S, Farnsworth K, Hayna JT, Duoos L, Fahning ML. A comparison of electroejaculation and epididymal sperm collection techniques in stallions. Can Vet J 2004;45:35-41.

[33] Dell'Aqua Jr JA, Papa FO, Alvarenga MA, Zahn FS. Effect of packing systems and thawing temperature on spermatic parameters and fertility rate of frozen equine semen. Revista Brasileira de Reprodução Anim 2001;25:458-60.

[34] Harrison RAP, Vickers SE. Use of fluorescent probes to assess membrane integrity in mammalian spermatozoa. J Reprod Fertil 1990;88:343-52.

[35] Ellington JE, Jones AE, Davitt CM, Scheider CS, Brisbois RS, Hiss GA, et al. Human sperm function in co-culture with human, macaque or bovine oviduct epithelial cell monolayers. Hum Reprod 1998;13:2797-804.

[36] Petrunkina AM, Gehlhaar R, Drommer W, Waberski D, TopferPetersen E. Selective sperm binding to pig oviductal epithelium in vitro. Reproduction 2001;121:889-96.

[37] Wagner A, Ekhlasi-Hundrieser M, Hettel C, Petrunkina A Waberski D, Nimtz M, Töpfer-Petersen E. Carbohydrate-based interactions of oviductal sperm reservoir formation-studies in the pig. Mol Reprod Dev 2002;37:140-3.

[38] Martins RHG, Goncalves TM, Madeira SL, Dias NH, Semenzati GO. Scanning electron microscopy of the tongue, pharynx, and larynx of rats exposed to cigarette smoke. J Voice 2014;28:287-90.

[39] Parra-Forero LY, Mendoza GD, Góngora A, López Fernández MDC, Cruz LA, Montiel AJ, Kjelland ME, García-Contreras ADC. Azteca Breed Horse epididymal sperm evaluation: a comparison of head, corpus and cauda sperm quality. Adv Reprod Sci 2015;3:57-65.

[40] Mizuno Y, Isono A, Kojima A, Arai MM, Noda T, Sakase M, Fukushima M, Harayama H. Distinct segment-specific functions of calyculin A-sensitive protein phosphatases in the regulation of cAMP-triggered events in ejaculated bull spermatozoa. Mol Reprod Dev 2015;82:232-50. 
[41] Gibb Z, Aitken RJ. The impact of sperm metabolism during in vitro storage: the stallion as a model. Biomed Res Int 2016;2016: 9380609.

[42] Amaral A, Lourenço B, Marques M, Ramalho-Santos J. Mitochondria functionality and sperm quality. Reproduction 2013;146:R163-74.

[43] Frenette G, Lessard C, Sullivan R. Selected proteins of "prostasomelike particles" from epididymal cauda fluid are transferred to epididymal caput spermatozoa in bull. Biol Reprod 2002;67:308-13.

[44] Rodriguez-Martinez H, Kvist U, Ernerudh J, Sanz L, Calvete JJ. Seminal plasma proteins: what role do they play? Am J Reprod Immunol 2011;66(Suppl. 1):11-22.

[45] Tiplady CA, Morris LHA, Allen WR. Stallion epididymal spermatozoa: pre-freeze and post-thaw motility and viability after three treatments. Theriogenology 2002;58:225-8.

[46] Gloria A, Carluccio A, Petrizzi L, Noto F, Contri A. Characteristics of frozen epididymal spermatozoa from stallions that died 12 to 36 hours after colic surgery. Theriogenology 2016;85:345-50.

[47] Peña Jr S, Summers P, Gummow B, Paris DBBP. Oviduct binding ability of porcine spermatozoa develops in the epididymis and can be advanced by incubation with caudal fluid. Theriogenology 2015; $83: 1502-13$.

[48] Blash S, Melican D, Gavin W. Cryopreservation of epididymal sperm obtained at necropsy from goats. Theriogenology 2000;54:899-905.

[49] Petrunkina AM, Simon K, Gunzel-Apel AR, Topfer-Petersen E. Kinetics of protein tyrosine phosphorylation in sperm selected by binding to homologous and heterologous oviductal explants: how specific is the regulation by the oviduct? Theriogenology 2004;61: 1617-34.

[50] Suarez SS. Formation of a reservoir of sperm in the oviduct. Reprod Domest Anim 2002;61:249-57.

[51] Leemans B, Gadella BM, Stout TAE, Sostaric E, Schauwer C, Nelis H, Hoogewijs M, Soom AV. Combined albumin and bicarbonate induces head-to-head sperm agglutination which physically prevents equine sperm-oviduct binding. Reproduction 2016;151: 313-30.

[52] Ekhlasi-Hundrieser M, Schafer B, Kirchhoff C, Hess O, Bellair S, Müller P, Töpfer-Petersen E. Structural and molecular characterization of equine sperm-binding fibronectin-II module proteins. Mol Reprod Dev 2005;70:45-57.

[53] Suarez SS. Mammalian sperm interactions with the female reproductive tract. Cell Tissue Res 2016;363:185-94.

[54] Henry F, Eder S, Reynaud K, Schön J, Wibbelt G, Fontbonne A Müller K. Seminal fluid promotes in vitro sperm-oviduct binding in the domestic cat (Felis catus). Theriogenology 2015;83: 1373-80.

[55] Gürler H, Malama E, Heppelmann M, Calisici O, Leiding C, Kastelic JP, Bollwein $H$. Effects of cryopreservation on sperm viability, synthesis of reactive oxygen species, and DNA damage of bovine sperm. Theriogenology 2016;86:562-71.

[56] Chen S, Einspanier R, Schoen J. Long-term culture of primary porcine oviduct epithelial cells: Validation of a comprehensive in vitro model for reproductive science. Theriogenology 2013;80:862-9. 